\title{
浅析生本理念下的初中英语语篇教学模式
}

\author{
钟妍妍 \\ 江西省赣州市兴国县第六中学 \\ DOI:10.32629/jief.v2i10.2309
}

[摘 要] 生本教学理念即以生为本的教学, 教学活动的开展需要围绕学生的个体化差异以及多元化需求, 该理念在初中英语教学中的应用有 利于更好地促进学生发展, 可明显调动学生的学习热情。为此, 教育者应该在充分了解该理念应用价值的基础上, 将其合理应用于英语语篇 教学中, 以提高教学质量

[关键词] 生本理念; 语篇; 教学

中图分类号: G633 文献标识码: A

在初中英语语篇教学课堂中, 仍然存在不少新的问题叒待解决, 有 些学生英语底子薄, 课堂效率不高; 有些学生厌倦英语, 经常上课缺课 或者是打乱英语课堂教学纪律等等, 而随着国际交往日益频繁, 英语作 为国际交流中的通用语言, 其作用和地位不容小雐, 许多英语教师感慨 英语难教, 英语语篇教学更是难上加难, 教学效果甚微, 学生也觉得英 语语篇难学, 所掌握的英语知识和技能的运用差强人意, 为改变这种学 习现状, 引用生本理念教学方式是十分必要的。

\section{1 生本理念教学的概念}

生本理念教学是指以学生为主体, 高度尊重和依靠学生, 让学生自 主地对知识行探索的现代教学方式, 它强调教师和学生的角色进行实质 性地转变, 恢复学生学习的主体地位, 教师由原本的教学者转变为导学 者, 学生的学习习惯则由原来的被动学习转变为主动学习, 这种教学模 式摆脱了传统观念的束缚, 为学生的学习提供了良好的学习环境和学习 动力, 促使学生的个性和潜能得到充分地发挥。

\section{2 生本教学理念的应用价值}

2.1 有助于调动学生积极性

在传统教学模式下, 教育者对课堂的主导性较强, 存在填鸭式教学 的问题, 忽略了学生受教育者主体的地位, 不注重与学生的交互, 未切 实调动学生的主观能动性, 导致学生英语学习兴趣缺乏。而基于生本教 育理念, 能够以尊重、关爱学生的方式, 将学生的思维导入课堂, 并可 通过给以学生适当的自主权限, 鼓励学生进行自主学习, 不仅可以有效 激发学生的学习热情, 还有助于提高其自主学习能力。另外, 根据学生 实际情况开展教学工作也能够为学生预留充分的自主探究与复习时间, 有利于学生复习巩固与拓展延伸。

\section{2 有助于构建和谐师生关系}

生本教学理念强调师生间的和谐, 旨在构建起以生为本的良好师生 关系。以往教学模式下, 教育者与学生间普遍为统治关系, 而初中生正 处于青春期, 存在较强的逆反心理, 故在该模式下, 很容易造成学生对 英语学习产生抵触心理。英语作为一门语言, 其在学习时也需要师生、 生生进行有效交互, 采用生本教学理念, 则可构建起平等、和谐的师生 关系, 能够进一步提高双方沟通的有效性, 这对于教学与激励有效性的 提升是有着显著促进作用的。

\section{3 开展基于生本理念下的初中英语语篇教学}

\section{1 强调学生的课前预习}

为了让学生深刻地理解英语语篇的内容, 需要初中英语教师布置与 英语语篇相关的预习作业, 可以要求学生查阅参考资料等方式, 找出文 中难词、词组或者重要的句型, 把重要的词句积累到练习本上, 利用零 散时间反复记忆, 做到在语篇中学单词, 记词句。例如: 在八年级下 Unit 6 中, 学生可以根据文中的情景、图片, 积累下 I' ve been collecting coins for seven years. He's been skating for five years 这样的 句型, 给现在完成进行时的语篇教学课堂打好基础, 在积累固定短语 more and more 时, 学生可以通过查阅资料或者是独自思考进行造句, 灵活运用这一短语。学生经过自主预习和探究, 才能为语篇教学做好铺 垫, 才能在教学过程中效果明显。
3.2 教师灵活导入知识, 激发学生学习兴趣

兴趣是学生最好的老师, 初中英语教师在语篇课堂教学中, 应该特 别注重学生学习兴趣的激发和相关知识的导入。在英语语篇教学前可以 采用多种途径引导学生自主地把重心放在所学内容上, 例如: 利用图片、 多媒体、讲故事、自由交谈等方式直观地进行导入。例如: 在学到语篇 谈论国内外中学生繁重的课余学习压力以及来源时, 英语教师可以通过 书信的方式来导入所学内容, 设置好两位不同国家的笔友, 通过书信来 阐述学生在学习过程中所遇到的问题, 并设置好问题, 如: ask students to read the letter and find what pressure she has. 这样学生就能 很快地找到这样的信息, She has to take part in after school clubs. She finds it hard to talk with her parents. Her parents send him to English and Science classes. etc. 这样的呈现方式为学生的阅读 提供了素材, 为学生和文章内容搭建起了桥梁, 书信贴近学生的日常生 活, 可以假发学生的学习兴趣, 同时, 也丰富了学生的语篇知识。

3.3 分组讨论并随堂测验

英语教师可以将学生进行分组, 并根据语篇教学中重难点内容进行 提问, 每个小组各有不同的任务, 促使学生自主的进行阅读, 随后进入 讨论阶段, 在英语教师的引导下, 学生相互之间自行进行问题解答, 深 入讨论问题且每个学生都有回答问题的机会。同时, 英语教师还可以设 置不同的检测题目测验学生对语篇的掌握和理解程度, 让学生把所学知 识消化吸收, 在这一环节中学生是主要的参与者, 教师只是一个引导者、 保护者。

\section{4 生本理念下的初中英语语篇教学课堂应注意的问题}

教师应关注每一位学生, 欣赏每一位学生, 抓住每一位学生的心理 特点, 让每位学生在教师的激励下不断自我超越, 了解学生兴趣爱好, 扑捉学生的闪光点, 让学生自由地发展, 同时, 在语篇课堂教学中, 将 课堂归还给学生, 教师只是努力维持平等自由的讨论教学秩序并给与学 生鼓励, 让学生自由地去讨论、去学习, 培养学生的学习积极性, 在感 悟中进行知识学习, 当然, 教师备课则要下足功夫, 要有前瞻性, 对学 生在上课过程中各种可能的问题和答案进行预见, 促使学生自己解决分 析好问题, 鼓励学生大胆的发表自己的一件, 激发学生的思维灵感, 促 使课堂教学洋溢出全新的局面。

总之, 作为教师, 我们必须要从整体上把握语篇的内容和功能, 用 科学的教学方法, 高效扎实的课堂教学结构培养学生, 训练学生, 使学 生真正能够理解课文, 才能够极大地提高学生的阅读能力, 从而进一步 提高学生综合运用语言的能力。

\section{[参考文献]}

[1]宋文锦.初中英语和小学英语教学衔接策略分析 [J]. 新课 程,2020(37):41.

[2]董佳佳. 英文歌曲引入小学英语教学初探 [J]. 河南教育(基教 版),2020(09):57.

[3]梁小萍.小学英语教学中如何构建 “少教多学” 的有效课堂[J].新 课程,2020(34):22. 